\title{
POSSIBILIDADES E LIMITES DA TEORIA DE JOYCE TRAVELBEE PARA A CONSTRUÇÃO DE UMA
} METODOLOGIA DE CUIDADO À FAMÍLIA

\section{POSSIBILITIES AND LIMITS OF JOYCE TRAVELBEE'S THEORY FOR THE CONSTRUCTION OF A FAMILY CARE METHODOLOGY \\ POSIBILIDADES Y LÍMITES DE LA TEORIA DE JOYCE TRAVELBEE PARA LA CONSTRUCCIÓN DE UMA METODOLOGÍA DEL CUIDADO DE LA FAMILIA}

\section{Maria Angélica Pagliarini Waidman ${ }^{1}$, Ingrid Elsen ${ }^{2}$, Sonia Silva Marcon ${ }^{3}$}

RESUMO: Este estudo, de natureza teórico-reflexiva, tem por objetivo apresentar a teoria de Joyce Travelbee e analisar suas limitações e potencialidades, com o propósito de construir uma metodologia de cuidado à família. Para o seu desenvolvimento fizemos uma explanação sobre a teoria englobando os conceitos, crenças e pressupostos da autora. Foi ainda realizada uma revisão de vários autores que utilizaram a teórica em seus estudos científicos e finalmente apresentamos uma reflexão a partir da análise da teoria, explicitando suas possibilidades e seus limites e como ela pode ser utilizada como suporte para o desenvolvimento de uma metodologia de cuidado às famílias de pessoas com transtornos mentais, com vistas à desinstitucionalização e a sua reinserção na família e comunidade.

PALAVRAS CHAVE: Família; Empatia; Teoria de enfermagem; Enfermagem psiquiátrica.

ABSTRACT: This is a theoretical, reflexive study that has as its aim to present Joyce Travelbee's theory and to analyze its limitations and potentialities, with the purpose of building a family care methodology. To do so, I made an explanation of the theory including the author's concepts, beliefs and principles. I have also performed a review of several authors that used this theories in their scientific studies and I finally present a reflection begining with the theory analysis, its expliciting its possibilities and its limits and how it can be used as a base for the development of a care methodology for families that have members with mental disorders, aiming at taking these people from the mental institutions and reinserting them in their families and community.

KEY WORDS: Family; Empathy; Nursing theory; Psychiatric Nursing.

RESUMEN: Éste es un estudio teórico y reflexivo que tiene como objectivo presentar la teoría de Joyce Travelbee y para analizar sus limitaciones y potencialidades, con el propósito de la construcción de una metodología del cuidado de la familia. Para hacer así pues, hice una explicación de la teoría incluyendo los conceptos, la creencia y los principios del autora. También he realizado una revisión de autores que utilizaron este teorías en sus estudios científicos y finalmente presento una reflexión con el análisis de la teoría, sus posibilidades y sus límites y de cómo puede ser utilizada como base para el desarrollo de una metodología del cuidado para las familias que tienen miembros con los desórdenes mentales, teniendo como objetivo a reinserción en sus familias y comunidad.

PALABRAS CLAVE: Familia; Empatía; Teoría de enfermería; Enfermería Psiquiátrica.

\footnotetext{
${ }^{1}$ Enfermeira, Doutora em Enfermagem, docente do Departamento de Enfermagem da Universidade Estadual de Maringá. Maringá/PR ${ }^{2}$ Enfermeira, Doutora em Enfermagem, professora da Universidade do Vale do Itajaí. UNIVALI. Itajaí/SC

${ }^{3}$ Enfermeira, Doutora em enfermagem, Docente do Departamento de enfermagem da Universidade Estadual de Maringá. Maringá/PR
} 


\section{INTRODUÇÃO}

O ser humano não vive sozinho, mas num contexto social, em que a família é sua rede de suporte mais próxima. Por isso, para cuidá-lo não se pode deixar de vê-lo como um todo e integrante desse contexto. Assim, com vistas a um cuidado mais efetivo, já não se cuida mais somente da pessoa, mas da família e dos seus membros.

Apesar de a família conviver com a saúde e a doença, existem determinadas patologias que abalam de forma incontestável sua estrutura e organização. A partir de nossa experiência profissional percebemos que a família sofre por não saber como lidar com as dificuldades de convivência com o portador de doença crônica, nesse caso específico, o transtorno mental. Esse pensamento é corroborado por NASI et al (2004) ao colocar que a família enfrenta situações de dificuldade talvez por não ter conhecimento suficiente sobre a doença e por não compreender a sintomatologia do seu familiar com transtorno psíquico.

Preocupadas com a problemática de como cuidar da família do portador de transtorno mental desenvolvemos este estudo, de natureza teóricoreflexiva, que tem por objetivo apresentar a teoria de Joyce Travelbee e analisar suas limitações e potencialidades, com o propósito de construir um referencial teórico-metodológico de cuidado à família.

Joyce Travelbee foi uma enfermeira psiquiátrica, educadora e escritora, nascida em 1926 e falecida em 1973. Apesar da vida curta, sua contribuição para a enfermagem foi muito grande. Obteve o título de enfermeira em 1946 na University of New Orleans - USA. Em 1952 iniciou a carreira como educadora da enfermagem, ensinando Enfermagem Psiquiátrica em New Orleans. Em 1959 recebeu o título de mestre em Enfermagem pela Louisiana State University (MELEIS, 1997).

Travelbee começou a publicar artigos sobre a enfermagem em meados de 1960. Em 1966 publicou seu primeiro livro Interpersonal Aspects of Nursing, reeditado em 1971, em que discute o relacionamento interpessoal. Em 1969 publicou seu segundo livro, que em Espanhol recebeu o nome de Intervencion en Enfermeria Psiquiatrica. Em 1973 começou o programa de doutorado na Flórida, mas não conseguiu terminá-lo, pois morreu prematuramente nesse mesmo ano (MELEIS, 1997).

Travelbee teve forte influência do catolicismo, e isto resultou numa valorização do cuidado espiritual da pessoa sob o cuidado da enfermeira. No que refere ao relacionamento interpessoal, foi influenciada por Jean Orlando - sua orientadora no mestrado. Sua teoria está também fortemente embasada em Viktor Frankl, ou seja, nos conceitos da logoterapia.

\section{Crenças, pressupostos e concepções}

Acreditamos que para entender o pensamento da autora é preciso falar um pouco da obra de Viktor
Frankl, que influenciou o seu trabalho. Em seu livro Psicoterapia e sentido da vida, Victor Frankl define a logoterapia como uma [...] "ciência que procura a conscientização do espiritual através de uma análise existencial, ou seja, ela se esforça para trazer o ser humano à sua consciência de seu ser-responsável enquanto fundamento essencial da existência humana" (FRANKL, 1986, p.55). O problema do sentido da vida é algo essencialmente humano e que, se a pessoa não consegue encontrá-lo, isto pode levá-la a um abatimento profundo, comprometendo assim sua saúde. A religião é uma forma de a pessoa encontrar o sentido para a vida e esta dimensão humana está diretamente relacionada ao amor.

Frankl (1986) refere ainda que o ser humano pode encontrar o sentido na vida a partir de três categorias de valores: criadores, vivenciais e de atitude. A primeira se realiza mediante um fazer, a segunda diz respeito à vivência de "eu com o mundo - natureza, e a terceira só se realiza quando algo de inelutável, ou seja, qualquer fatalidade tem que ser aceita como ela é. É através deste pensamento que ele acredita que a vida humana pode atingir sua plenitude não apenas no criar e gozar, mas também no sofrimento" (FRANKL, 1986, p.149). O autor destaca ainda que o ser humano tende a relacionar a falta de êxito na vida com falta de sentido, e isto não é verdade. Esta própria falta de êxito significa uma vivência, talvez uma vivência de dor e não-plenitude, mas com certeza uma experiência de crescimento pessoal (FRANKL, 1986).

É possível perceber que Travelbee não se baseou em Frankl apenas no tocante a seu conceito de sentido na vida e significado na doença, mas também na sua concepção de amor, presença forte em seus pressupostos. TRAVELBEE (1979) traz algumas definições em sua teoria que acreditamos ser importante discuti-las para justificar a escolha dessa autora no trabalho com famílias. Apesar da época em que a escreveu, apresenta idéias atuais no trabalho com portadores de transtornos mentais, tanto que, é uma das autoras mais usadas como referencial teórico na área de enfermagem psiquiátrica, no Brasil.

Assim apresentamos os pressupostos de sua teoria com o propósito de compreender melhor o pensamento da autora, são eles: 1 - A finalidade do cuidado profissional é conseguida através do estabelecimento do relacionamento pessoa-a-pessoa. 2 - Somos seres humanos únicos, mas similares em nossa natureza. 3 - A maioria das pessoas experimentará - pelo menos uma vez na vida em uma ou outra situação - a alegria, a felicidade e o amor. 4 - Todos os seres humanos vivenciarão a doença e a dor e morrerão um dia. 5 - A qualidade e a quantidade do cuidado oferecido ao paciente são influenciadas pela percepção da enfermeira e do paciente. 6 - Os termos: paciente e enfermeira são estereótipos (termo que se refere a julgamento, preconceitos e rótulos que os seres humanos tendem a desenvolver em relação aos outros) úteis somente 
para facilitar a comunicação. 7- Para estabelecer o relacionamento terapêutico, é necessário ir além dos papéis de enfermeira e paciente. 8- A doença e o sofrer são experiências espirituais, físicas e emocionais. 9- A enfermeira estabelece um relacionamento através da comunicação o que lhes permite cumprir a finalidade dos cuidados. 10 - A enfermeira pode ajudar as pessoas a encontrar um significado na sua doença e assim ajuda-los a lidar com ela. 11-. A bagagem filosófica da enfermeira ajuda o doente e a sua família a encontrar um significado na experiência de doença. 12 - É de responsabilidade da enfermeira ajudar o doente e sua família a encontrar significado no sofrimento e na doença (TRAVELBEE,1979).

Ao falar de estereótipos na relação enfermeirapaciente, a autora quer advertir as enfermeiras de que elas não devem pensar no paciente ou cliente como tal, mas como seres humanos que naquele momento necessitam de assistência de outros seres humanos que podem oferecer essa assistência a fim de ajudá-los, por isso a denominação é só uma característica do momento.

Quanto aos conceitos centrais de sua teoria, é possível perceber uma congruência e relação entre eles, o que poderá ser observado na discussão a seguir. A sua definição de enfermagem psiquiátrica foi destacada em seu primeiro livro Interpersonal Aspects of Nursing e rediscutida e complementada em seu segundo livro Intervencion en enfermeria psiquiátrica, considerada como:

"[...]um proceso interpersonal mediante el cual la enfermera ayuda a una persona, familia o comunidad con el objeto de promover la salud mental, prevenir o afrontar la experiencia de la enfermidad $y$ el sofrimiento mental $y$, si es necesario, contribuye a descubrir un sentido a estas experiencias...constituye un proceso interpersonal que se ocupa de personas". Estas personas pueden ser pacientes individuales, familias o grupos que necesitan la ayuda que la enfermera puede ofrecer (TRAVELBEE, 1979, p. 5).

É possível perceber que a sua abordagem dentro da enfermagem psiquiátrica é ampla, envolvendo não só a pessoa do doente, mas tudo e todos que o cercam. Coloca que a tarefa do profissional é ajudá-los a encontrar um significado para a experiência. Esta concepção é fundamental para ajudar a família a aceitar a patologia e encontrar caminhos para enfrentá-la. Este "encontrar sentido na experiência" faz com que a pessoa doente e sua família busquem dentro de si forças capazes de mudar a realidade, pois vários estudos (SCHNEIDER, 2001; KOGA, 1997; OLIVEIRA, 2001; ROSA, 2001, OLIVEIRA, 2002; MORENO \& ALENCASTRE, 2002) descrevem que as famílias apresentam dificuldades no relacionamento com o portador de transtornos mentais, desconhecimento de sinais, sintomas e etiologia da doença, falta de habilidade para lidar com situações como agressividade e alterações do humor, alterações no sono (de todos os membros familiares) provocadas pela excitabilidade do doente, e a necessidade de mudança de hábitos e rotinas das famílias após o aparecimento do transtorno mental.

Ao falar sobre o conceito de saúde, TRAVELBEE (1979) discute a definição da Organização Mundial da Saúde (OMS), dizendo que esta é um juízo de valor que tange à natureza do ser humano e, esses juízos são definidos como normas culturais, regras e comportamentos dentro de uma sociedade, significando que eles não são estáticos, mas formados por concepções vigentes sobre ele e sua natureza, ou seja, sobre a sociedade na qual esse ser humano vive.

A autora, ao falar de suas crenças sobre a natureza da saúde mental, destaca a importância de três qualidades: capacidade para amar, para enfrentar a realidade e para descobrir um propósito ou sentido na vida. A primeira delas é considerada a mais importante, pois se não amarmos a nós mesmos e os demais não podemos desenvolver nossa atividade profissional com êxito. $\mathrm{Na}$ segunda, enfrentar a realidade, salienta que a principal função da enfermeira é ajudar a pessoa a identificar seus problemas e a enfrentá-los de forma realista, e assim reconhecer seu papel na experiência e encontrar soluções práticas para os problemas da vida.

TRAVELBEE (1979) acredita que a doença ajuda as pessoas a compreender sua limitação e condição humana. Esta sua concepção está embasada na crença de que a experiência de doença ajuda o ser humano a crescer e se fortalecer, reconhecendo assim sua limitação e potencialidade. A experiência de doença leva a pessoa a compreender sua própria vida levando-o a encontrar, a partir dela, as forças interiores necessárias para a luta travada na recuperação ou adaptação a uma situação que não pode ser mudada. Mas esse adaptar-se, na visão da autora, não tem o sentido de conformismo, mas de realmente compreender e aceitar sua realidade e limitação.

Em relação à terceira capacidade - que é a de encontrar um propósito e sentido para a vida destaca que a função da enfermeira neste campo é ajudar as pessoas a desenvolver uma filosofia de vida que lhes dê sustento nos momentos de pressão e sofrimento. Para ela, o transtorno mental é um uma experiência vivida pelo ser humano que não pode ser experimentada como um rótulo, devendo a pessoa ser aceita e respeitada pelos que a cercam.

Ao definir a enfermeira, TRAVELBEE (1979) a identifica como uma pessoa com conhecimento, interessada em ajudar os outros e a si mesma, em prevenir enfermidades, promover a saúde e ajudar os doentes a encontrar um sentido na vida, a partir de sua enfermidade. É possível perceber que este conceito está associado à sua concepção de enfermagem já descrita anteriormente. 
Quanto ao ser humano, a autora o considera como um ser único, com características únicas, com certas necessidades humanas e fisiológicas básicas que devem ser satisfeitas para a sua sobrevivência e o alcance da saúde mental. É possível perceber uma congruência em seus conceitos, sendo que o seu foco central está na relação terapêutica e no encontro do significado ou sentido na doença e na vida TRAVELBEE (1979).

A concepção de ser humano é um dos pontos mais importantes de sua teoria, pois é a partir desta concepção de unicidade que ela valoriza a compreensão e aceitação das pessoas como elas são, respeitando suas individualidades, limitações e potencialidades. É preciso destacar que este conceito precisa ser considerado não só para a pessoa do doente, mas também para a enfermeira que irá relacionar-se com ele.

A comunidade tem papel fundamental na recuperação do portador de transtorno mental, por isso coloca que a enfermeira e a família ajudam o paciente na recuperação da saúde. Para essa autora a comunidade é definida como um grupo de pessoas que vivem dentro de uma área geográfica determinada e que se relacionam entre si. Refere ainda que a atenção oferecida pela enfermeira pode ser individual ou grupal - que engloba também a família - direta ou indireta. Na atenção direta ela pode ajudar as pessoas a enfrentarem a pressão imposta pelo sofrimento da doença, e na atenção indireta ela ajuda as pessoas a conhecerem os recursos disponíveis na comunidade. Além disso, pode atuar como instrutora da comunidade em assuntos de família (TRAVELBEE,1979).

A autora acredita ainda, que o cuidado da enfermeira ao paciente deve estar pautado no relacionamento humano, envolvendo a empatia, a simpatia e o rapport. Na segunda edição do seu livro Interpersonal Aspects of Nursing considera que a que a enfermeira deve procurar não somente aliviar a dor física do outro, mas transcender ao cuidado físico e ver a pessoa inteira, o seu sofrer, o seu estado mental e espiritual (THOMAS \& CARVALHO, 1999).

Quanto ao relacionamento terapêutico ou relação pessoa-a-pessoa, o descreve como uma meta a ser alcançada, sendo resultado final de uma série de interações planejadas entre os seres humanos - enfermeira e paciente - durante as quais estes desenvolvem uma capacidade crescente para estabelecer relações interpessoais. Destaca que uma das características desta relação é que ambos experienciam o crescimento e mudança de comportamento (TRAVELBEE, 1979)

Esta relação se diferencia de outras, por ter metas e objetivos a serem alcançados, sendo que uma das tarefas da enfermeira ao desenvolvê-la é definir o que quer alcançar durante a interação. Recomenda que as metas e os objetivos sejam identificados por escrito, bem como os métodos e meios que usará para alcançá-los, sendo eles: 1-
Identificar seus problemas; 2 - enfrentar os problemas presentes; 3 - perceber sua participação na experiência, e enfrentar de forma realista seus problemas; 4 - discernir alternativas e encontrar novas linhas de comportamento, para comunicar-se e socializar-se; e 5 - encontrar um sentido em sua enfermidade (TRAVELBEE, 1979).

Um outro ponto destacado pela autora, como fundamental para o êxito do relacionamento pessoaa-pessoa, é o compromisso dos envolvidos. Isto faz com que a relação seja única e original, já que cada momento não pode ser repetido. Para ela, a interação não pode existir sem compromisso. Comprometer-se, significa transcender-se e interessar-se pelo bemestar da outra pessoa. Quando se refere a transcender quer dizer que o seu compromisso vai muito mais além do esperado, que envolve $e$ ultrapassa todas as dimensões que envolvem a vida daquele ser humano. A enfermeira deve se preocupar com a pessoa como um todo, inclusive seu lado espiritual e relacional do mundo que a cerca (TRAVELBEE, 1979).

TRAVELBEE (1979) considera que cada ser humano experimenta um aprendizado onde cada um é afetado com pensamentos, sentimentos e comportamentos do outro. Daí pode-se inferir que o profissional ao trabalhar com famílias deve ter consciência de seus conceitos, pensamentos e atitudes, para que estes não interfiram na relação com o ser humano/família.

Apresenta ainda fases distintas no processo de relacionamento enfermeira-paciente:

1. Fase de pré-interação: a única em que não há participação do doente. É a fase em que a enfermeira identifica a pessoa e obtém as informações necessárias para o desenvolvimento do relacionamento. Nessa fase ela reconhece seus sentimentos, pensamentos e comportamentos, estando ciente de como eles podem interferir na relação. 2. Fase introdutória ou de orientação: é aquela na qual os dois seres humanos se conhecem e firmam compromisso de desenvolver o relacionamento terapêutico. É o momento de conhecer e compreender o outro, sua singularidade; é um momento único em que ambos experienciam crescimento pessoal. Essa fase termina quando um começa a ver o outro como ser humano único. Perceber o outro como tal na visão da autora ocorre quando ambos conseguem ver a singularidade $e$ unicidade de cada um, assim como os limites, potencialidades e peculiaridades enquanto seres humanos. Destaca ainda que neste sentido a enfermeira e o paciente usam toda a sua experiência anterior de forma a ajudá-los a compreender e aceitar o outro como único. 3. Fase de identidades emergentes: caracteriza-se pela resolução dos problemas encontrados na fase anterior, ou seja, é o desenvolvimento pleno do relacionamento pessoa-apessoa. Outra característica desta fase é que enfermeira e o doente se conhecem cada vez mais. 
Ela termina quando o enfermeiro percebe que seus objetivos estão sendo alcançados. 4. A quarta fase ou término: uma das suas características importantes é que a enfermeira deve lembrar o paciente do compromisso que fizeram; analisar o alcance dos objetivos propostos, a importância e motivos do término e prepará-lo para continuar independente no que for possível (TRAVELBEE, 1979).

Quando fala em enfrentar a realidade e encontrar um propósito ou sentido para a vida, a autora elenca alguns caminhos que a enfermeira precisa estabelecer com o paciente como o método indireto, que inclui parábolas (contar estórias semelhantes), abordagem velada do problema (uso de pronomes indefinidos) e abordagem da experiência pessoal (experiência compartilhada). No método direto, TRAVELBEE (1979) cita que ele também inclui perguntar brincando e explicando através do uso das técnicas de comunicação (através do uso de perguntas e comentários abertos, de técnica de reflexão, de percepções compartilhadas e de imagens).

O fato de ajudar a pessoa a encontrar sentido na sua enfermidade está embasado na sua crença de que a doença pode e deve ser uma experiência de crescimento e aprendizagem e que isto pode provocar na pessoa um desenvolvimento como ser humano - a partir da consciência de seu próprio sofrimento. Isto porque geralmente as pessoas doentes têm tendências a acusar a si mesmas e aos outros como causa da sua doença, culpam a Deus, a má-sorte, o destino, os amigos, a família e os companheiros de trabalho. A busca desta culpa faz parte da tentativa da pessoa em encontrar sentido para a sua doença e descobrir razões para o seu sofrimento, e esta é uma das tarefas da enfermeira, ou seja, ajudar o doente a enfrentar e suportar essa fase (TRAVELBEE, 1979).

O trabalho da enfermeira, por sua vez, segundo a autora, só será possível a partir do estabelecimento da comunicação. Comunicar-se com outra pessoa pode ser uma experiência significativa ou pode não ter nenhum significado, dependendo de como ela é desenvolvida. É através da comunicação que a enfermeira descobre a finalidade de seu cuidado, que ela ajuda os indivíduos e suas famílias a lidar com as experiências de doença e sofrimento e a encontrar um significado no sofrer.

Ao falar da comunicação com o paciente descreve algumas técnicas que a enfermeira pode levar em consideração, entre elas: saber a hora de falar e de calar-se; discutir temas relevantes e apropriados a cada situação; saber ouvir, mesmo que seus pensamentos divirjam dos pensamentos do outro; usar seus atributos pessoais, como caráter, a experiência anterior, o bom senso, o conhecimento científico e a preocupação com o bem-estar do paciente. É preciso, ainda, levar em conta as condições do paciente que está atendendo, ou seja, as características de sua patologia, por exemplo, a do deprimido - calado em função de sua patologia - a dificuldade de compreensão de determinados pacientes com déficit de inteligência, a dificuldade de comunicação do esquizofrênico em estado grave da doença e os próprios sintomas dos transtornos psicóticos como o delírio, a alucinação, a confusão mental e a agitação psicomotora. Com o passar do tempo, a enfermeira vai alcançando habilidade em comunicar-se, ou seja, entende aqueles que falam e faz com que sejam entendidos por eles mesmos e pelos outros. Quando TRAVELBEE (1979) fala em fazer com que os pacientes sejam entendidos por eles mesmos e pelos outros, se refere àqueles que têm déficit de comunicação por causa de sua patologia, por isso ajudá-los a se comunicar é uma das tarefas da enfermeira psiquiátrica.

Para desenvolver uma relação efetiva com o outro é preciso que a pessoa esteja aberta, o que implica ser capaz de permitir que coexistam problemas ou sentimentos opostos, que levem a busca de uma solução através da reflexão. Alerta para a importância de a enfermeira, antes de iniciar a relação com o doente, estar atenta para os seus pensamentos e sentimentos para que estes não interfiram na relação de maneira negativa, porque cada pessoa participante é afetada e afeta o comportamento, sentimento e pensamento do outro. É neste sentido que a autora ressalta a necessidade de a enfermeira usar a si mesma, isto é o "eu terapêutico" (TRAVELBEE, 1979). Mas para que isto aconteça é preciso que ela esteja ciente de seus valores, crenças e sentimentos, pois assevera que a qualidade do tratamento oferecido a cada paciente é determinada pelas crenças da enfermeira em relação a enfermidade, sofrimento e morte, e que os valores espirituais dela e suas crenças filosóficas são fatores determinantes para auxiliar os pacientes a encontrarem significado em casos de doença e sofrimento.

Com relação à pessoa da enfermeira, ela deve usar sua capacidade e seus conhecimentos científicos, experiências e vivências anteriores. Quanto ao doente, deve estar disposto a desenvolver o relacionamento de ajuda respondendo ao esforço do profissional de acordo com sua capacidade. Mas no que se refere ao doente, é preciso levar em conta o tipo de problema que tem ou está enfrentando, tanto no que tange ao comprometimento causado pela patologia, como por exemplo, alguns tipos de demências e o estágio da doença, quanto a sua disposição para aceitar se relacionar com a enfermeira. Destaca quatro funções da enfermeira psiquiátrica; a primeira delas é a de promover a saúde mental; a segunda é de prevenir que a mesma surja; a terceira é de ajudar o doente a enfrentá-la e a última é de assistir o paciente, sua família e comunidade, ajudando-os a encontrar o verdadeiro sentido na enfermidade (TRAVELBEE, 1979).

Estes conceitos e pressupostos foram apresentados com base na crença de que eles 
explicitam o pensamento da autora e é a partir desta compreensão, que pretendemos delinear alguns passos em direção à construção do referencial teórico-metodológico e com isso refletir a prática de enfermagem com famílias com base nesse referencial.

\section{Estudos que utilizaram o referencial teórico de Travelbee: possibilidades e limites da teoria}

É muito comum, no Brasil, o uso do referencial teórico de Travelbee pelos enfermeiros que trabalham em psiquiatria, contudo as escolas de enfermagem são aquelas que a utilizam com maior freqüência na disciplina de saúde mental e/ou enfermagem psiquiátrica. Nos últimos anos os conceitos desta autora também foram adotados por profissionais/pesquisadores de outras áreas da enfermagem e isto, segundo eles, se deu pela preocupação com o ser humano doente e em desenvolver uma assistência de enfermagem humanizada.

THOMAS \& CARVALHO (1999) ao usar o referencial de Travelbee para oferecer cuidado humanizado a pacientes terminais justificam essa escolha pela forma abrangente como ela propõe a assistência ao ser humano, ou seja, visando atender às necessidades biológicas, emocionais, psicológicas e espirituais através da ênfase no amor, na esperança, na comunicação e no relacionamento, como forma de encontrar um sentido para as vivências. O estudo, além de objetivar um cuidado de enfermagem a clientes em fase terminal baseado nos pressupostos da teoria de Travelbee, buscou também uma nova abordagem da dinâmica de cuidar, que valoriza as ações interativas da equipe e desencadeie a um processo de reflexão sobre os cuidados oferecidos por enfermeiros e professores de enfermagem aos clientes em fase terminal. As autoras destacam que a aplicação dos pressupostos da teoria permitiu a reflexão sobre a morte, levandoos, tanto aos doentes quanto à equipe, a aceitá-la como um momento da vida, descobrindo assim seu sentido e significado.

Travelbee também tem sido adotada como uma das preferidas por enfermeiras que trabalham com doentes crônicos ou terminais. BECK (1995), por exemplo, a utilizou em seu trabalho com familiares de pacientes internados em unidade de terapia intensiva abordando o processo de viver, adoecer e morrer. Ao desenvolver a investigação, a autora teve por objetivo aplicar a teoria de Travelbee com o intuito de construir uma metodologia de assistência de enfermagem aos familiares dos pacientes internados em terapia intensiva. Seu estudo foi embasado no pressuposto de que a dor e o sofrimento têm um significado no processo de viver (BECK, 1995). Assim, buscou refletir com os familiares suas angústias e medos relacionados ao adoecer e morrer, constatando que cada família expressava sua dor e sofrimento de maneira diferente. Para entendê-la melhor é preciso compartilhar sua dor utilizando a empatia o que favorece o desenvolvimento de uma assistência humanizada.

DURMAN (2000) também utilizou o referencial de Travelbee associando-o a alguns conceitos e pressupostos de STEFANELLI (1993) para desenvolver uma relação de ajuda terapêutica tendo em vista a humanização da assistência a pacientes internados em hospital. Para o desenvolvimento da pesquisa usou os conceitos de TRAVELBEE (1979), quais sejam, a atitude para amar, a capacidade para enfrentar a realidade e a capacidade para encontrar sentido ou significado na vida. DURMAN (2000) conclui que a relação de ajuda terapêutica enfermeira-paciente faz com que o receptor do cuidado sinta-se aceito e valorizado como ser humano, que promove seu crescimento e minimiza as dificuldades vivenciadas em decorrência da doença e hospitalização.

Ao desenvolver sua pesquisa envolvendo docentes, discentes e equipe assistencial de enfermagem, GRÜDTNER (1997), teve por objetivo ajudar a família do indivíduo que necessita de intervenção cirúrgica. Utilizou para tanto os pressupostos e conceitos da pedagogia problematizadora de Paulo Freire e da teoria da relação interpessoal de Travelbee, também vislumbrando o encontro de um significado e sentido na doença e na vida. Destaca que a escolha do referencial teórico se deu pelos conceitos de amor e comunicação dos autores os quais envolvem a humildade, o diálogo, a cooperação e a parceria.

Em função de problemas encontrados pelo número insuficiente de enfermeiras ao serviço, COOK (1989) desenvolveu nos Estados Unidos um estudo, que demonstrou a utilidade da teoria na avaliação do sofrimento de enfermeiras devido ao estresse do trabalho. Ela utilizou a teoria para definir a natureza, o grau do sofrimento e a natureza de cada fase do desenvolvimento de interações significativas entre membros de um grupo de enfermeiras que se encontravam regularmente para discutir o estresse de seu trabalho. O estudo foi realizado através de um plano de intervenções baseado em Travelbee com o intuito de aliviar o sofrimento, redefinir a situação e a descobrir significados em suas experiências através de abordagens disciplinadas e intelectuais e do uso do próprio interesse. COOK (1989) concluiu que o desenvolvimento da interação e das intervenções ajudou os membros do grupo a se sentirem menos vitimados e ganhar o controle sobre suas vidas profissionais. $O$ trabalho resultou ainda na melhoria da auto-estima, na resolução de problemas, na melhora do ambiente de trabalho que ficou mais agradável e amigável e, finalmente, na redescoberta de um novo sentido no desempenho das atividades profissionais, caracterizado por maior autonomia na execução de papéis e por posturas mais desafiadoras. O resultado do estudo forçou o hospital 
a buscar um novo sistema no tratamento dos pacientes.

$\mathrm{Na}$ área da Enfermagem psiquiátrica, o referencial de Travelbee já foi utilizado em vários estudos (STEFANELLI, 1993; RODRIGUES, 1996; RODRIGUES, 1999; FENILI; 1999; FENILI, 2000; WAIDMAN, 1998; WAIDMAN et al, 1998), entre outros. FENILI (1999) ao desenvolver uma assistência de enfermagem ao cliente psiquiátrico utilizando o referencial teórico das necessidades humanas básicas e o da relação interpessoal de Travelbee, verificando que a observação é extremamente importante, pois a partir daí foi possível orientar, direcionar e avaliar a assistência prestada ao cliente através de uma relação terapêutica alicerçada no fazer da enfermeira. Destaca que o relacionamento interpessoal é a ferramenta essencial para o desenvolvimento da assistência de enfermagem, e que as pessoas envolvidas devem ser reconhecidas como seres humanos únicos, com suas próprias singularidades e especificidades, merecendo respeito e consideração.

WAIDMAN et al (1998) objetivando conhecer como a teoria de Joyce Travelbee estava sendo utilizada na prática da disciplina Saúde Mental e Enfermagem Psiquiátrica de uma universidade pública, realizaram um estudo com docentes e discentes. Os resultados mostraram que, ao desenvolverem o relacionamento terapêutico com os portadores de transtornos mentais, os alunos encontram algumas dificuldades, que foram superadas no decorrer do processo, pois a habilidade de se comunicar e se relacionar com os demais foi adquirida com a prática. As autoras observaram ainda que através do desenvolvimento do relacionamento terapêutico seja possível crescer enquanto ser humano, que a experiência de relacionar-se desta forma é descrita pelos entrevistados como uma lição de vida, e que os pressupostos apreendidos para empregar no relacionamento, com a pessoa com essa patologia, podem ser estendidos a todos os relacionamentos do enfermeiro e que, agindo desta forma é possível tornar a assistência de enfermagem individualizada e humanizada.

FALLEIROS (1996) por sua vez desenvolveu o relacionamento interpessoal terapêutico com o portador de transtorno mental crônico. O estudo foi realizado com o objetivo de encontrar caminhos que pudessem tornar o relacionamento terapêutico uma prática do dia-a-dia da enfermagem psiquiátrica. Concluiu que o desenvolvimento deste relacionamento é capaz de promover mudanças comportamentais, levando o portador de transtorno mental a se relacionar melhor consigo mesmo e com os outros, pois a relação criou espaço para transformações. Assevera que as características crônicas da doença continuam, mas a postura e a relação da doente com o mundo mudaram, ou seja, ela encontrou um significado e sentido para sua experiência de dor e sofrimento dentro do hospital psiquiátrico.

$\mathrm{Na}$ análise dos estudos realizados utilizando esta autora, é possível perceber que a escolha por ela se deu principalmente pela sua forma integralizada e humanizada de ver o ser humano. Outro ponto também destacado por todos os autores, diz respeito ao encontro do sentido e significado da doença e da própria vida. A análise feita a esse respeito é de que a autora tem sido escolhida porque de alguma forma ela mostra um caminho para a melhoria da qualidade da assistência oferecida ajudando a quem precisa, seja o doente, sua família ou a comunidade de uma forma geral, a aceitar as condições impostas pela doença que não podem ser mudadas, mas ao mesmo tempo busca encontrar um significado nesta experiência, encontrando um sentido para viver melhor e com qualidade.

MELEIS (1997) refere que nas décadas de 60 e 70 , ou seja, logo após Travelbee ter desenvolvido sua teoria, foram realizados muitos estudos nos Estados Unidos, utilizando os conceitos de empatia, principalmente para medir o grau da mesma e, a maioria deles concluiu que faltavam alguns constructos para a validade de previsão do instrumento e a confiabilidade era baixa. Porém, a autora cita os estudos de Stetler desenvolvidos em 1970, de Mcbride em 1967 e de Freihofer e Felton em 1976 como alguns que testaram a teoria no que tange não só à empatia, mas ao desenvolvimento da interação quando envolve dor e sofrimento, em que verificou que a teoria oferece subsídios para confortar, apoiar e aliviar o sofrimento do paciente e de seus familiares. MELEIS (1997) acredita que o desenvolvimento deste tipo de estudo pode oferecer dados para explorar a validade da teoria para as enfermeiras e para os pacientes.

Essa última autora ao discutir a teoria de Travelbee faz algumas críticas importantes que oferece subsídios para refletir e pensar na possibilidade de complementá-la. Como ponto positivo da teoria MELLEIS (1997) apresenta os seguintes aspectos: 1- aborda um dos conceitos mais importantes da enfermagem, qual seja o relacionamento e a interação; 2- os conceitos da teoria são congruentes com os valores ocidentais; 3as hipóteses são claras e harmoniosas com os conceitos e as propostas teóricas; 4- a concepção de humanidade, enfermagem, problemas de enfermagem e tratamento terapêutico da enfermagem são claros conceitualmente sendo a integridade de suas suposições preservadas em todas as definições, 5- os conceitos são claros e têm seu valor.

Os pontos negativos apontados por MELEIS (1997) atribuídos a teoria de Travelbee se relacionam a : 1- baixo poder de explicação da teoria; 2- ser parcimoniosa, ou seja, poupa explicações de como as etapas acontecem; 3- o alcance é limitado, pois restringe sua aplicação quando a pessoa a ser ajudada está inconsciente; 4- a falta da visão 
biológica do paciente em sua teoria limita sua utilidade e aceitação por parte das enfermeiras; 5que os limites da teoria não são claros ou definidos operacionalmente.

\section{REFLEXÕES FINAIS}

A partir do exposto, é possível identificar que, embora alguns aspectos sejam discutíveis com relação a teoria proposta por Travelbee, os positivos tem sido relevantes no auxilio de enfermeiros na abordagem de algumas situações, particularmente pelo apoio das concepções de unicidade do ser humano, relacionamento interpessoal com comprometimento emocional, comunicação autêntica e verdadeira e encontro de significados na doença e nas dificuldades surgidas no decorrer da vida, os quais mantêm relações entre si.

A experiência em desenvolver atividades de cunho teórico-científico com base no referencial de TRAVELBEE (1979) em saúde mental e na enfermagem psiquiátrica tem mostrado que na assistência à pessoa com transtorno mental é fundamental a valorização das relações entre os seres humanos. Isso faz com que a referida teoria seja muito atual e prática, pois é reconhecido o fato de que o transtorno mental não tem etiologia definida. Várias causas interferem para que ela se instale no ser humano e vários são os fatores que podem ajudar este a se recuperar.

Por outro lado, mesmo referindo que o trabalho com o portador de transtorno mental deve envolver a comunidade e que a família faz parte desta, a autora não apresenta sua concepção de família e de como pode ser 0 trabalho com ambas. Por isso, concordamos com Meleis quando fala que a autora poupa explicações em como esse processo pode ser conduzido, apontando assim lacunas que deverão ser preenchidas em estudos futuros.

Alguns estudiosos (ELSEN, 1994; MARCON et al 2004; GOMES 1994) que desenvolvem pesquisas com famílias, ressaltam que o profissional precisa ter uma compreensão clara do próprio conceito de família. Isto é essencial, pois muitas vezes, se ele não tiver clareza de suas concepções teóricas, as informações recebidas e observações realizadas darão uma visão distorcida da realidade familiar. Isto se intensifica ainda mais no processo de desinstitucionalização em que nem sempre os interesses familiares de manter o doente em casa são congruentes com os do hospital. Isto foi descrito por OLIVEIRA (2001) quando se refere ao déficit de comunicação apresentado entre a família e os profissionais da instituição, mostrando que as famílias não estão satisfeitas com o atendimento recebido, apontando assim uma lacuna, ou seja, a falta de assistência à família. Esta preocupação é expressa por AMARANTE (1996) e MORGADO \& LIMA (1994) quando estes afirmam que para a desinstitucionalização acontecer é necessário o estabelecimento de cuidados aos doentes e suas famílias.

O trabalho com famílias não pode ser definido de forma rígida e sem espaço para a criatividade, porque as famílias são diferentes entre si. Apesar de existirem problemas comuns, as pessoas que os vivenciam e o ambiente em que eles acontecem são diferentes, por isso devem ser conduzidas de formas diferentes e individualizadas, de preferência com base na realidade de cada um, como, por exemplo, levando em consideração as crenças, valores, cultura e o conhecimento específico daquela família. É neste sentido que acreditamos que os pressupostos de Travelbee podem ser úteis, pois na sua proposta de relação interpessoal e comunicação ela propõe a compreensão do outro como um todo, ou seja, como ele é nas suas potencialidades e limitações. Nesse sentido a autora não faz distinção do papel desempenhado pelos seres humanos, quer sejam profissional, doente ou família, colocando que a diferença entre eles é que um precisa de ajuda e o outro pretende ajudar. Consideramos essa visão importante para compreender o outro e ajudá-lo a encontrar caminhos para a melhoria da qualidade de vida, tanto da família como do próprio profissional.

Travelbee aponta que é papel da enfermeira atuar como instrutora da comunidade em assuntos de família, porém não explicita como fazê-lo, neste sentido, estudos visando melhor compreensão deste papel, seu conteúdo, estratégias são igualmente requeridos para a complementação da teoria.

Apesar de os escritos de Travelbee serem anteriores as discussões sobre desinstitucionalização ocorridas no mundo, ela traz em sua teoria a preocupação com o trabalho comunitário da enfermeira, tanto na prevenção quanto da reabilitação do doente. Apesar de suas idéias serem inovadoras até para nossos tempos, pensamos que o fenômeno da desinstitucionalização e da reinserção social precisa ser incorporado ao trabalho da teórica.

Uma outra lacuna que percebida na teoria está relacionada à parceria ou ao compartilhar de saberes, que não é discutido por Travelbee. Apesar de estas questões estarem implícitas em seus escritos, elas precisam ser esclarecidas e explicitadas, pois na experiência na abordagem de famílias de pessoas com transtornos mentais esse aspecto é fundamental. Corroboramos com o pensamento de ESPERIDIÃO (2001) quando diz que as iniciativas que procuram redefinir o papel dos profissionais e dos serviços de saúde, carecem de uma discussão sobre o significado do cuidado em Saúde Mental, criando uma cultura de solidariedade e vivência de cidadania que garanta a inclusão social do indivíduo e sua família resguardando sua autonomia e dignidade.

Acreditamos que, ao criar essa cultura é possível compartilhar conhecimentos dos integrantes da família, da família como um todo e os da enfermeira encontrando soluções ou caminhos para a resolução de algumas dificuldades. No momento, em 
WAIDMAN, M. A. P.; ELSEN, I.; MARCON, S. S. Possibilidades e limites da teoria de joyce travelbee para a construção de uma metodologia de cuidado à família. Revista Eletrônica de Enfermagem, v. $08, \quad$ n. $02, \quad$. 282 - $291,2006 . \quad$ Disponível em http://www.fen.ufg.br/revista/revista8_2/v8n2a13.htm

que há uma perspectiva de mudança na forma de tratar a pessoa em sofrimento psíquico, valorizando os serviços extra-hospitalares e a manutenção dela o maior tempo possível no domicílio, compete aos profissionais buscar o desenvolvimento de metodologias de cuidado para as famílias favorecendo a desinstitucionalização.

\section{REFERÊNCIAS BIBLIOGRÁFICAS}

AMARANTE, P. O movimento de reforma psiquiátrica no Brasil. In: O homem e a serpente: outras histórias para a loucura e a psiquiatria. Rio de Janeiro: Ed. da Fiocruz, 1996.

BECK, C.L.C. O processo de viver, adoecer e morrer: Reflexões com familiares de pacientes internados em uma unidade de terapia intensiva. 1995. Dissertação [Mestrado] Centro de Ciências da Saúde. Universidade Federal de Santa Catarina, Florianópolis, 1995.

COOK, L. Nurses in crisis: a support group based on Travelbee's nursing theory. Nursing and health care. Philadelphia. v.10, n.4, 1989, p.203-205.

DURMAN, S. Enfermeiros assistenciais construindo a relação de ajuda terapêutica em hospital geral. 2000. Dissertação [Mestrado] Centro de Ciências da Saúde. Universidade Federal de Santa Catarina. Florianópolis, 2000.

ELSEN, I. Desafios da enfermagem no cuidado de famílias. In. BUB, L.I.R. (Coord). Marcos para a prática de enfermagem com famílias. Florianópolis: Ed.da UFSC, 1994.

ESPERIDIÃO, E. Assistência em saúde mental. A inserção do familiar na assistência psiquiátrica. Revista Eletrônica de Enfermagem [online], Goiânia, 2001. Disponível em: http://www.fen.ufg.br/revista/revista3 1/samental.html [Acesso em 30 jul. de 2005].

FALLEIROS, M.N.R.B. Travessia para o amanhã: relacionamento interpessoal terapêutico com o doente mental crônico. 1996. Dissertação [Mestrado] Centro de Ciências da Saúde. Universidade Federal de Santa Catarina. Florianópolis, 1996.

FENILI R.M. O (des)encanto de uma relação estabelecida com uma cliente internada em uma instituição psiquiátrica. Nursing Edição Brasileira, São Paulo, n.30, p.24-27, 2000.

FENILI, R.M. Desvelando necessidade contrária através da assistência de enfermagem ao cliente psiquiátrico. 1999. Dissertação [Mestrado] Centro de Ciências da Saúde. Universidade Federal de Santa Catarina. Florianópolis, 1999.

FRANKL, V.E. Psicoterapia e sentido da vida: fundamentos da logoterapia e análise existencial. 2 ed. São Paulo: Quadrante, 1986.

GOMES, V. Educação para a família: uma proposta de trabalho preventivo. Rev. Bras. Cresc. Des. Hum., São Paulo, v.4, n.5, p.34-39, 1994.

GRÜDTNER, D.I. Processo educativo participativo com enfoque na ajuda à família: uma experiência na disciplina de enfermagem cirúrgica. 1997. Dissertação [Mestrado] Centro de Ciências da Saúde. Universidade Federal de Santa Catarina, 1997.

KOGA, M. Convivência com a pessoa esquizofrênica: sobrecarga familiar. 1997. Dissertação [Mestrado] Escola de Enfermagem, Universidade de São Paulo, Ribeirão Preto, 1997.

MARCON, S.S. et al. Compartilhando a situação de doença: o cotidiano de famílias de pacientes crônicos. In: ELSEN, I., MARCON, S.S. (Org.). O viver em família e sua interface com a saúde e a doença. $2^{\mathrm{a}}$ ed. Maringá: Eduem, 2004.

MELEIS, A.I. On interactions. In: .Theoretical nursing developmente \& progress. New York: Lippincott, 1997.

MORENO, V.; ALENCASTRE, M.B. Vivencia do familiar da pessoa com sofrimento psíquico. In: Congresso Internacional Pesquisando a Família, 2002.Florianópolis. Resumos...Florianópolis; [S.n.], 2002. p.35.

MORGADO, A.; LIMA, L.A . Desinstitucionalização: suas bases e a experiência internacional. Jornal brasileiro de Psiquiatria, Rio de Janeiro, v.43, n.1, 1994.

NASI, C; STUMM, L.K \& HILDEBRANDT, L.M. Convivendo com o doente mental psicótico na ótica do familiar. Revista Eletrônica de Enfermagem. 2004 [online]. Disponível em: http://www.fen.ufg.br/revista/revista6 1/f6 mental.htm I [Acesso em 06 mar. 2006].

OLIVEIRA, A.M.N. Expectativas da família frente a facticidade da doença mental In: Congresso Internacional Pesquisando a Família, 2002.Florianópolis. Resumos... Florianópolis; [s.n.], 2002. p.64

OLIVEIRA, A.M.N. Os sentimentos da família frente a facticidade da doença mental. Fam. Saúde e Desenv. Curitiba, v.3, n.2, p.154-162, 2001.

RODRIGUES, A.R.F. Enfermagem psiquiátrica: saúde mental prevenção e intervenção. São Pulo: EPU, 1996.

RODRIGUES, A.R.F. Relações interpessoais terapêuticas na enfermagem. Ribeirão Preto: Scala, 1999.

ROSA, L.C. dos S. Um portador de transtorno mental no ciclo de vida familiar. 2001. Tese [Doutorado] Departamento de Serviço Social. Universidade Federal do Rio de Janeiro. Rio de Janeiro, 2001.

SCHNEIDER, J.F. Ser família de esquizofrênico: o que é isto? Cascavel: EDUNIOESTE, 2001.

STEFANELLI, M.C. Comunicação com o paciente: teoria e ensino. São Paulo: Robe, 1993.

THOMAS, C.T.; CARVALHO, V.L. O cuidado ao término de uma caminhada. Santa Maria: Palloti, 1999.

TRAVELBEE, J. Intervención en enfermeria psiquiatrica. Carvejal: Cali, 1979.

WAIDMAN, M. A. P. Enfermeira e família compartilhando o processo de reinserção social do doente mental. Florianópolis. 1998. Dissertação 
WAIDMAN, M. A. P.; ELSEN, I.; MARCON, S. S. Possibilidades e limites da teoria de joyce travelbee para a construção de uma metodologia de cuidado à família. Revista Eletrônica de Enfermagem, v. 08, n. 02, p. 282 - 291, 2006. Disponível em http://www.fen.ufg.br/revista/revista8 2/v8n2a13.htm

[Mestrado] - Centro de Ciências da Saúde. Universidade Federal de Santa Catarina.

Florianópolis, 1998.

WAIDMAN, M. A.P.; STEFANELLI, M C; JOUCLAS, V M G. O caminhar com a teoria de Joyce Travelbee na prática de enfermagem psiquiátrica: desvelando uma experiência. Cogitare Enfermagem, Curitiba, v.3, n.1, p.7- 12, 1998.

Artigo recebido em 10.07.2006

Aprovado para publicação em 31.08.2006 